University of Louisville

ThinkIR: The University of Louisville's Institutional Repository

$5-2014$

\title{
Graphic design in the United States targeting Hispanic
} consumers.

\author{
Chelsea Vaal \\ University of Louisville
}

Follow this and additional works at: https://ir.library.louisville.edu/honors

Part of the Fine Arts Commons

\section{Recommended Citation}

Vaal, Chelsea, "Graphic design in the United States targeting Hispanic consumers." (2014). College of Arts \& Sciences Senior Honors Theses. Paper 76.

http://doi.org/10.18297/honors/76

This Senior Honors Thesis is brought to you for free and open access by the College of Arts \& Sciences at ThinkIR: The University of Louisville's Institutional Repository. It has been accepted for inclusion in College of Arts \& Sciences Senior Honors Theses by an authorized administrator of ThinkIR: The University of Louisville's Institutional Repository. This title appears here courtesy of the author, who has retained all other copyrights. For more information, please contact thinkir@louisville.edu. 
Graphic Design in the United States:

Targeting the Hispanic Consumer

By

Chelsea Vaal

Submitted in partial fulfillment of the requirements

for Graduation summa cum laude and for Graduation with Honors from the Department of Fine Arts.

University of Louisville

March, 2014 
One in six United States citizens (almost seventeen percent of the population) identifies themselves as Hispanic. ${ }^{1}$ As this demographic continues to grow in numbers and expand its influence on the country, it is worth exploring how to better target this audience. Many advertising and design agencies are already reaching out to U.S. Latinos, but are they doing so effectively? Although more companies are attempting to reach out to this demographic, their attempts may be unsuccessful. Understanding what makes these advertisements successful or unsuccessful can be extremely effective in determining how to better target the Hispanic market. An analysis of Hispanic culture and design reveals that designers and advertisers can more effectively target the Latino audience by achieving a deeper understanding of the group. This paper examines how to effectively target the Hispanic audience based on insight into their culture, culminating in a design project that puts this information into practice.

\section{Defining the Terms "Hispanic" and "Latino"}

"Are you Hispanic or Latino? It's a question Hispanics and non-Hispanics alike have struggled with when deciding what to call the diverse community of 53 million Americans who trace their roots to Latin America or to Spain."2

- Mark Hugo Lopez, Pew Research Center

Much controversy and confusion surrounds the use and definition of the terms "Hispanic" and "Latino". There have been many discussions about which term should be

1 "Hispanic Fast Facts," last modified September, 2013, https://ahaa.org/default.asp?contentID=161.

2 Mark Hugo Lopez, "Hispanic or Latino? Many don't care, except in Texas," Pew Research Center, October 28, 2013, accessed March 24, 2014, http://www.pewresearch.org/fact-tank/2013/10/28/in-texas-its-hispanic-por-favor. 
used, but there does not seem to be a general consensus. The United States government has officially used both terms since 1997, and many members of the group seem to identify with both. "Hispanic" occurs more frequently in many of the marketing and advertising sources used for this project, so it is used more often in this paper, since this is the background from which this project comes.

In this paper, both of these terms are used to describe people who are from or who have ancestors from Spanish-speaking countries and/or identify with the cultures of these areas. This is not a racial, but an ethnic distinction, based on shared values and traditions rather than physical characteristics. There are issues that arise when using this terminology, however, due to the diversity within this group. These terms attempt to define a group with members so different from one another that one word cannot effectively describe it. Suzanne Oboler shares her opinion on this issue by stating, "the ethnic label “'Hispanic'...reduces their distinct relations among themselves and with the society of the United States to an ethnic label that in fact fails to do justice to the variety of backgrounds and conditions of the populations to whom it has been applied". ${ }^{3}$ Each Hispanic country has its own unique culture and although there is some mixing among these cultures when they are brought to this country, it is still important to recognize the diversity among them. The shortcomings encountered by using these general terms are understood, but it is necessary to have some way of identifying the group as a whole. The use of these terms does not connect to a belief in or promotion of the homogenization of this group, but rather rises out of the necessity to define the group in some way.

\footnotetext{
${ }^{3}$ Richard Delgado and Jean Stefancic, The Latino/a Condition: A Critical Reader (New York: New York University Press, 1998), 9.
} 


\section{Why Target a Hispanic Audience?}

"Entrepreneurs and corporate executives across America are awakening to the importance of Hispanic consumers and their growing purchasing power, estimated to reach $\$ 1.5$ trillion dollars by $2015^{\prime \prime}$

- Glenn Llopis

The Hispanic market in the United States is constantly growing in size and importance, making it imperative that businesses invest in targeting this segment of the population if they want their companies to continue to grow and thrive. "The Hispanic advertising industry...is outpacing all other sectors of advertising, with four times the amount of growth." 5 The majority of growth in the advertising industry in this country today comes from advertisements reaching out to the Hispanic American population. Businesses and brands that recognize this fact are more likely to see a higher rate of growth for their companies. According to an article in Food Product Design, "consumer packaged goods brands that focus on Hispanic marketing are most likely to see more rapid topline revenue growth than those who are not as focused on the market."6 Brands and companies that effectively target the Hispanic market will see a higher increase in revenue than those that do not. Studies also show that people from this cultural background are more likely to develop brand loyalty, and spend more time and money at the grocery than the average consumer. ${ }^{7}$ Therefore, loyal Hispanic consumers can prove to be extremely valuable for companies. Although it takes more time and money initially to target this

4 Llopis, "Capturing the Hispanic Market."

5 "Hispanic Fast Facts."

${ }^{6}$ IBID

7 “CPG Companies Target Hispanics for Growth," Food Product Design, March 12, 2012. 
audience due to the amount of research that is necessary, if it is done correctly, marketing directed towards Latinos can greatly influence a company's success.

The power of this demographic comes from its numbers. The U.S. Census Bureau estimated the Hispanic population in the United States at around 50 million (about seventeen percent of the total population) in 2011, and this number is expected to continue to grow. By 2060, the Hispanic population is expected to reach 128.8 million, which would be about thirty percent of the country's population. ${ }^{8}$ The group's large numbers allow it to hold considerable influence in American society. As the Hispanic population in the United States expands, it continues to gain more power and influence in our society, and it is in companies' best interests to appeal to members of this group as effectively as possible.

Targeting U.S. Latinos provides obvious benefits for these consumers as well as for companies. They feel more connected to a brand or company that embraces their values and takes the time to understand them. Ronnie Lipton states, "Design that's inclusive, and targeted, is important for any ethnic group whose members have been made to feel like outsiders."9 Targeting the Hispanic population allows them to feel more integrated into American culture, especially in a society where they often face racism and prejudice.

Furthermore, this faction comprises too large a percentage of our population to be ignored. As a country that prides itself on being a melting pot of different people from around the world, we should embrace the cultures they bring with them, not push them aside. When

8 "The Hispanic Population in the United States," United States Census Bureau, last modified November 6, 2012, accessed September 7, 2013, http://www.census.gov/ population/hispanic/data/2011.html

${ }^{9}$ Ronnie Lipton, Designing Across Cultures (Cincinnati, OH: How Design, 2002), 9. 
we target the Hispanic consumer, we show that we respect this demographic and the culture it carries with it.

Additionally, Latinos may not interpret and understand advertisements in the same way as others residing in the United States. They come from a different background, and therefore interpret information in a unique way. Toni O’Bryan explains, “People often assume, mistakenly, that the arts are truly universal...that great art will naturally be appreciated by all, no matter which culture is exposed to it. They forget that the arts- and design- are also part of a person's set of cultural understanding of the world and its reality." 10 Latinos may approach information from a different perspective than Americans from other cultural backgrounds, and therefore interpret it in unique ways. It is necessary to target the Hispanic market because its members often respond in different ways than others residing in the United States.

\section{Hispanic Culture}

"It's taking a step back and understanding them, listening to them, knowing what makes them tick, and then begin to react."11

- Juan Tornoe, owner and senior consultant at Hispanic Trending

As with any group, the most effective way to make a connection with the target audience is to understand it as much as possible. This is especially important when reaching out to the Hispanic demographic as a nonmember since there is so much to learn about the culture. Effectively reaching out to this group requires extensive research that

${ }^{10}$ Audrey Bennett, "Compartiendo Sueños," in Design Studies, ed. Audrey Bennett (New York: Princeton Architectural Press, 2006), 295.

11 “An Interview with Juan Tornoe," Latino Branding Power, March 28, 2011. 
examines its values, family structure, religious beliefs, and other important aspects that provide a better understanding of the everyday lives of its members.

A homogenous Hispanic culture does not exist. What we often consider to be Hispanic culture is an over-simplified amalgamation of the various cultures and entities that make up Spanish-speaking America. Although there is some mixing and homogenization among these different groups once they come to the United States, it is important to remember that an attribute of one sub-group of Hispanic culture may not apply to the group as a whole. We can identify overarching characteristics that apply to most Latinos, which helps us to better understand this demographic. These generalizations help when targeting a wider audience if we de not rely too heavily on them. There are several characteristics common to the Hispanic population that help to better understand this group's culture, lifestyle, and values.

Family stands as the most important and widely recognized value in U.S. Latino culture. Those that identify themselves as Hispanic or Latino place a strong emphasis on family and community. People in the United States tend to emphasize individuality and independence, but this is not the case with many people of Hispanic descent. "There is an emphasis on cooperation and interdependence among family members and individuals are encouraged to sacrifice individual needs for the benefit of the family."12 Latinos normally have close relationships with their families and rely on their family members for support.

12 Charlotte Shoup Olsen and Linda Skogrand, "Cultural Implications and Guidelines for Extension and Family Life Programming with Latino/Hispanic Audiences," The Forum for Family and Consumer Issues 14 (2009): 1, accessed March 23, 2014, http://ncsu.edu/ffci/publications/2009/v14-n1-2009-spring/olsen-skogrand.php. 
Although family values are important to many in the United States, the family unit is an integral aspect of Hispanic culture.

Many Hispanic households place great value on the role of the mother. Hispanic families normally hold a tremendous amount of appreciation for a mother's influence, especially regarding raising children and maintaining the home. Ronnie Lipton states, "in Hispanic cultures in general, reverence and respect for the mother is paramount."13 Mothers are greatly valued in Hispanic society due to the role they play in Hispanic households. Embracing the role of the Hispanic mother can be an effective marketing tool, since she is such an integral aspect of the Hispanic household. Thomas Weyr says, "The role of the Hispanic mother is the key. She makes all the buying decisions with the exception of beer, liquor, and cigarettes, and she cannot be reached in the same way or with the same methods that attract the Anglo woman."14 Mothers hold a strong influence in many Hispanic households, and are a powerful part of this market in the United States.

Hispanic society also traditionally places less importance on careers than many in the United States. While many residents of the United States "live to work," many people in Hispanic countries or from Hispanic backgrounds "work to live."15 In the United States, we often uphold a career as the most important aspect of a person's life, but many Hispanics uphold their families as the most important aspect of their lives, with their careers serving only as a means to provide for their families. This quality further demonstrates the strong family ties that exist in Hispanic culture.

13 Lipton, 36.

14 Thomas Weyr, Hispanic U.S.A.: Breaking the Melting Pot (New York: Harper \& Row, 1988), 183.

15 Arturo A. Fox, Latinoamérica: Presente y Pasado (Upper Saddle River: Prentice Hall, 2011), 145. 
Religion is also an incredibly important value in Hispanic culture. Faith and religious beliefs play a larger role within this group than in the culture of the United States. According to The Hispanic Way, "in the Hispanic world, religion traditionally has played a greater role in the social life and daily activity of the people than in our culture."16 Many Spanish-speaking countries incorporate their faith into society and popular culture, unlike the United States, where there is a more clearly defined line between church and state. Roman Catholicism is extremely prevalent in many Hispanic countries, and is therefore common among Latinos in the United States as well. Its influence is beginning to dwindle, however, as many U.S. Latinos convert to Protestantism or leave their faith behind. Time magazine explains that two-thirds of the Hispanic-American population today identifies as Roman Catholic, but this ratio is expected to reduce to around half by 2030.17 Protestantism especially is beginning to rise among the Hispanic population in the United States, with Protestant evangelical churches popping up all over the country. Although religion and the Catholic faith especially continue to influence Hispanic culture in the United States, it is necessary to recognize the changes affecting religion among U.S. Latinos.

Along with recognizing the values that many Hispanic consumers share, it is helpful to understand differences within the group in order to target a more specific audience within the demographic. Many areas of the United States have a higher population of one specific ethnicity or nationality within the larger Hispanic identity, and it can be beneficial to target one of these groups in areas where they have a large presence. According to Richard Delgado and Jean Stefancic, "most Mexican Americans reside in the Southwest,

16 Noble and Lacasa, 74.

17 Elizabeth Dias, "Evangélicos," Time Magazine, April 15, 2013, accessed March 23, 2014, http://content.time.com/time/subscriber/article/0,33009,2140207-1,00.html. 
California, and the Midwest, most Puerto Ricans in New York and other East Coast cities, and most Cubans in Florida." 18 In many cases it may be more beneficial to target advertisements towards a specific nationality such as Mexican, Cuban, or Puerto Rican in areas with higher populations of these specific nationalities. Instead of creating one ad that attempts to embrace all U.S. Latinos, creating separate ads for more specific demographics often proves more successful.

As we identify what makes the Hispanic population unique, we must remember that while U.S. Latinos identify with Hispanic culture, they also identify with the culture of the United States. When targeting a Hispanic audience, we must not exclude them from the culture of the United States in our attempts to engage with their culture. Thomas Weyr's discussion of the "separate and assimilate" syndrome in Hispanic U.S.A. seems to successfully sum up the attitude of many Latinos in the United States towards this issue: Weyr states, "they want to assimilate and to remain separate, to be part of the mainstream and to remain their own identity."19 This is the paradox that makes this demographic so difficult to reach. Although they want to maintain aspects of their Hispanic culture, they do not want to be ostracized from the culture of the United States. The key to reaching this demographic is to find that delicate balance between the two. We must take their Hispanic heritage into consideration, but we must also recognize that they are a part of society in the United States as well.

Understanding of Hispanic culture grows by comparing it to its perception in the United States today. Stereotypes (defined as widely held but fixed and oversimplified

18 Delgado and Stefancic, 3.

${ }^{19}$ Weyr, 1. 
images or ideas of a particular type of person or thing) have a huge influence on how this culture is perceived in our society. ${ }^{20}$ Ruth E. Zambrana states, "Stereotypes... affect the discriminatory way in which public policies are designed and implemented to decrease their access to public resources." 21 The way we portray Latinos in advertising and the media can have a significant effect on how they are perceived and treated in our society. We have an obligation to represent this culture accurately, because we are in part responsible for how they are viewed in our society. Audrey Bennet describes the effects of advertisements on peoples' perceptions: "Considering the cultural effect of advertisements, the downside of using stereotypes is that they fossilize shared beliefs about people even though they may be wrong or negative."22 By including stereotypes in designs, designers not only alienate their audience, but they also perpetuate these misconceptions in our society. Stereotypes should be avoided not only because the consumer will not respond to them, but also so that we do not contribute to the incorrect portrayal of Latinos in the media in the United States. It is imperative to break through these stereotypes and learn to appreciate this group and culture for what it truly is. Although it can be difficult to cast them aside, it is important to disregard them as much as possible to form a more accurate view of this demographic and to give its members the respect they deserve.

Many stereotypes concerning Hispanic culture are common in the United States. For example, the careers of Latinos are often stereotyped in U.S. society. They are frequently

20 Oxford Dictionaries, accessed March 23, 2014, http://www.oxforddictionaries.com/us/definition/american_english/stereotype.

${ }^{21}$ Ruth E. Zambrana, Latinos in American Society: families and communities in transition (Ithaca: Cornell University Press, 2011), 16.

${ }^{22}$ Audrey Bennett, "Mediating Messages," in Design Studies, ed. Audrey Bennett (New York: Princeton Architectural Press, 2006), 279. 
portrayed as gardeners, maids, construction workers, or other low-wage occupations. Tanya Saracho explains, "We have such a limited view of who we are. We have stereotypical images that have been fed to us in TV, film, and commercials. In fact, we are 27 complicated, rich, diverse countries...but we are still viewed as the person who buses your table and who cleans up after your kids." ${ }^{23}$ Although many Hispanics hold careers other than those mentioned above, media and advertisements often portray them as holding these positions.

Another stereotype concerning U.S. Latinos that is common in our society is the misconception that they are all recent immigrants and/or illegal aliens. The U.S. Census Bureau shows, however, that only about thirty-six percent of the Hispanic population was foreign-born in 2011, meaning that the majority of Latinos in the United States were born in the country. ${ }^{24}$ Many people in the United States seem to believe that all, or at least a majority of Latinos have just crossed the Mexican border, but this is simply not the case. The Hispanic culture in the United States is comprised of people of various nationalities who have been in the country for varying lengths of time. Many areas of the United States with the highest levels of Latino population such as California and Texas were once a part of Mexico, and were Spanish territory before that. Most of these areas were annexed to the United States in 1847 as a result of the Mexican American War. ${ }^{25}$ Families in these states may have been in the same area for generations. It is important to reach out to recent

23 Wanda Medina, “Leading Role,"Latina, December 2013/January 2014, 40.

24 "Hispanic Americans by the Numbers," infoplease, last modified 2014, accessed February 27, 2014, http://www.infoplease.com/spot/hhmcensus1.html.

25 “The Mexican American War," PBS, accessed March 23, 2014, http://www.pbs.org/wgbh/americanexperience/features/general-article/grant-mexicanamerican-war. 
arrivals, but it is also imperative that Hispanics who have been in the country longer are not neglected or treated the same as those who have just arrived.

Another common misconception is that all Latinos are uneducated and illiterate. The Hispanic population traditionally does have a lower level of education than other groups in the United States, but this does not mean that they are unintelligent. Data from the United States Census Bureau suggests that $9.5 \%$ of the Hispanic population in the U.S. in 2013 had a bachelor's degree, which falls behind the non-Hispanic white population's $21 \%$, the Asian population's $28.6 \%$, and the black population's $12.6 \% .{ }^{26}$ Although Latinos fall slightly behind other groups in regards to education, many are still highly educated, and all can still respond intelligently to advertisements. According to Ronnie Lipton, "One persistent error in advertising to Hispanics is simplification to the point of insulting the audience's intelligence." 27 Some simplification can be helpful if you are targeting Hispanic consumers who speak little to no English, but many Hispanic Americans speak English well and would not respond well to being approached in this way. There are many Latinos with high levels of education and who hold positions of authority and power in the country. It is thoughtless to assume that all Hispanics are uneducated and illiterate.

The assumption that all U.S. Latinos identify with one homogenous Hispanic culture also continues to pervade the psyche of many in the United States. Designers and advertisers are at least in part responsible for this stereotype. According to Arlene Dávila, "the Hispanic marketing and advertising industry [is] one of the most influential forces

26 "Educational Attainment in the United States: 2013," United States Census Bureau, last modified January 7, 2013, accessed March 23, 2014, http://www.census.gov/hhes/socdemo/education/data/cps/2013/tables.html.

${ }^{27}$ Lipton, 17. 
behind [this idea]." 28 As discussed earlier, each Latin American country has a unique identity and culture that remains important to many Latinos in the United States.

Professionals involved with marketing and advertising have the power to either reinforce or overcome this false idea of sameness with their work. By reaching out to the Hispanic demographic, we can help other people in the United States to see how our society has falsely labeled and stereotyped this segment of the population.

Along with the idea of a homogenous Hispanic identity, an image has developed in the minds of many Americans of a typical Latino. You can clearly see this stereotypical image in Figure 1. The man pictured on this billboard for a radio station has a thick moustache and is wearing a sombrero, a string of bullets and a poncho, while surrounded by images of the Mexican flag and a donkey. Although these qualities may help consumers in the United States to immediately identify a figure as Hispanic, these images are not an accurate representation of the diversity and complexity that exists within the Hispanic community. The creator of this billboard clearly did not attempt to gain an understanding of Hispanic culture, resulting in an offensive advertisement that most likely turned away Hispanic listeners, and possibly those of other backgrounds as well. It may be easier to fall back on these stereotyped views of Hispanic culture, but the outcome will not be successful.

It is almost impossible for a nonmember of a group to disregard all of their stereotypes and preconceived notions, but having a better understanding of the culture helps to erase some of these inaccuracies from our minds. Studying what this demographic values allows for a more meaningful connection to be made with the consumer, and

${ }^{28}$ Delgado and Stefancic, 209. 
knowing how this group is inaccurately portrayed prevents potentially offensive advertising. It can also be helpful just to understand that you do not have a complete understanding of the culture, because you will be more likely to recognize stereotypes in your work if you recognize that they could appear. People who are members of the group can be beneficial resources as well to ensure that the advertisement provides an accurate view of the culture.

Understanding Hispanic culture is an integral aspect of targeting the Hispanic market. It is necessary to delve into the nuances of this group in order to avoid the inaccuracies that permeate many advertisements and designs that target this audience. As with all design and marketing, understanding the target audience is essential in determining the best way to reach them. For a Hispanic audience, this means understanding what makes Hispanic culture unique, while also recognizing the differences within this group. Latinos come from a rich cultural background that can effectively be used to reach out to this group if it is understood correctly.

\section{Design}

"At this time of globalization and rapid advances in technology, designers have a large responsibility to look outside of their own backyards and truly research how to conscientiously and respectfully communicate with other cultures."

- Toni O’Bryan

There are many aspects to consider when determining the best way to reach Hispanic consumers through design. The qualities discussed above provide a basic understanding of Hispanic culture, but it is also necessary to interpret these facts in a way that shows how these consumers will react and respond to different ideas or images. 
Cultural facts provide a framework for designs for this demographic, that must then be built upon with more specific insights into the audience. It is essential to move beyond just the facts to recognize the people that are behind them.

When considering the Hispanic American population, it is imperative to keep in mind the varying levels of acculturation among these consumers. While some Hispanics may have just arrived in the country, others have lived here their entire lives and may not even speak Spanish. A second or third generation Hispanic American may have a deep understanding of American culture, but a recent immigrant may not know much about the country. These differences must be addressed when making decisions about designs and advertisements, because they could significantly impact the way in which these consumers interpret the messages that are shared with them.

Hispanic Americans also respond more to different messages than other groups in the United States. Due to their distinct values, Latinos prefer messages that are more personal and focus on a direct benefit rather than solely on the product's qualities. According to Thomas Weyr, "Anglo advertising pushes product efficacy...Hispanic advertising focuses on personal benefit." 29 While many consumers in the United States respond more to a straightforward approach that directly addresses the product's attributes, many Hispanics respond more to personalized benefits. For example, if promoting a beauty product to Hispanics, it would be more effective to claim that it makes you look younger and beautiful instead of simply saying it will remove wrinkles. Latinos are more interested in establishing a personal connection with brands and companies. According to Glenn Llopis, “Hispanic consumers don't want to be sold to, they want to

${ }^{29}$ Weyr, 183. 
connect with brands that embrace their culture." ${ }^{30}$ Hispanic consumers want to establish a connection with the brands and products they buy, and to understand how the products relate to their lives.

It is also beneficial to consider what kind of benefits you are promoting. The values mentioned earlier reveal that Hispanic Americans may look for different benefits in products and services than Americans from other cultural backgrounds. For example, if attempting to promote a cleaning product that makes the cleaning process more efficient, instead of saying that it would give you more time to relax, it would be more beneficial to state that it would give you more time to spend with your family. Jesus Ramirez of Cartel Creativo calls this "the martyr syndrome," and it means that a message of convenience will only work if it focuses the concern on the family. ${ }^{31}$ It is important to remember what this demographic values in order to know what they will respond to.

Although there are many companies that are not embracing the growth that is possible by targeting the Hispanic consumer, there are some that successfully reach out to this demographic. These companies and designers can provide a good example of how to effectively address Hispanic Americans in marketing and design strategy. As with all other design, you can learn how to situate brands by looking at what already exists in the field. Targeting this demographic offers a unique experience, however, because you can look at designs in Hispanic countries as well as designs targeting Latinos in the United States.

Designs that originate in Hispanic countries can be valuable resources, but they also require some discernment, since consumers in the United States are at least slightly

${ }^{30}$ Llopis, "Capturing the Hispanic Market."

${ }^{31}$ Lipton, 26. 
removed from the cultures of these countries. Even if they were born in another country, U.S. Latinos often assimilate at least in part to the culture of the United States, and therefore can not be targeted in the same way as Latinos residing in Hispanic countries. However, these designs can still provide a background on marketing in Hispanic countries before moving forward to see how trends in these areas adapt themselves to life in the United States. Studying graphic design from both Hispanic countries and from the United States reveals several common traits among design targeted towards Hispanics.

The use of color is a defining characteristic in many designs that reach out to this audience. Although the Hispanic love for color is often overplayed, there is some validity behind this stereotype. As Xavier Burmúdez explains, "Like the fruit of Latin America, it is color that makes our designs stand out."32 Vivid colors are used in many designs to engage and excite the viewer. Figure 2 provides a good example of this through the use of color in posters for the Teatro Nacional Sucre. The simple forms in the designs are brought to life by the bright colors that are used to create them. Many Hispanic designers also utilize blocks of color in their designs, as demonstrated by Figures 3 and 4. Both of these designs use large areas of solid colors to create contrast within the works. Color is an extremely important and defining element of many Hispanic designs.

Many designs also include outlined forms that create a graphic appearance. Figure 4 demonstrates this quality, along with Figures 5 and 6 . These outlines create a unique appearance that is characterized by boldness and strength. Similarly, hand-drawn images, such as the posters for la Feria de libro filosófico (Figure 7) are also common in Hispanic

32 Felipe Taborda and Julius Wiedemann, Latin American graphic design (Hong Kong: Taschen, 2008), 8. 
design. ${ }^{33}$ Many of the designs already shared also have this element, which seems to make the images more personal and relatable. Numerous designs have hand-drawn lettering as well, which can be seen in Figures 4, 5, and 7. Outlines, hand-drawn images and lettering all create a more personal connection for the viewer, which is a concept that is important to Hispanics. Whereas photography and printed type may create a more impersonal and stoic appearance, hand-drawn elements form a more personable and engaging image.

References to indigenous cultures can also be found in Hispanic design. Care must be taken when employing this approach, however, because all Hispanics do not identify with the indigenous cultures of all Hispanic countries. This trait can be utilized if you are targeting a specific group within the Hispanic American demographic that will definitely be familiar with the culture, or if it is used in a way that will not ostracize other consumers. Enerchía (Figure 8) provides a good example of a successful integration of indigenous culture into design in the United States. According to Uno Branding's website, “The illustration seamlessly combines old and new worlds: chia plant, Aztec shaman, spa-like coloring and textures." ${ }^{34}$ This brand was created to target Hispanic Americans who are familiar with the Aztec culture and the chia plant, but other consumers can still understand the concept as well. Remnants of indigenous cultures often remain relevant and visible in modern Hispanic societies, so it can prove useful to adopt this tactic if you are targeting a more specific audience.

33 "Graphic design in Latin America, Part I; Colombia, Peru, Venezuela \& Mexico," A History of Graphic Design, accessed March 3, 2014, http://guitynovin.blogspot.com/2011/12/graphic-design-in-latin-america-part-i.html.

34 "Enerchia Health Drink," UNO Branding, last modified 2013, accessed March 2, 2014, http://www.unobranding.com/uno/amnistad/ 
Designs that do not effectively target this audience are also a good resource, because they can be used to understand what to avoid. Many ads that fail to reach the Hispanic consumer employ one or more of the stereotypes mentioned above. These ads are not successful because "in most cases, dropping in a visual cliché only conveys that the designer didn't take the time to look beyond the surface."35 Advertisements based on stereotypes show that those involved relied on their pre-existing view of the demographic, and were unwilling to spend the necessary time and money to gain a clear picture of their target audience. Hispanic consumers look for advertisements that show an appreciation and respect for their culture, and they understand that designs that include stereotypes do not promote a positive image of Latinos in the United States.

It is also important to ensure that advertisements provide correct information about the culture they are attempting to target. An advertisement that was created with good intentions can be ruined if the information that is included is incorrect. Ronnie Lipton shares a good example of why it is necessary to check facts in his book Designing Across Cultures. An advertiser created a television spot featuring a woman doing the Mexican hat dance. Although this sounds like a good attempt at embracing Mexican culture, the spot presented many inaccuracies. The woman was barefoot, although the dancer is always wearing shoes, and the costume she was wearing was not even Mexican. ${ }^{36}$ Although the spot never ran, it most likely would have offended consumers who were familiar with the dance. Stereotypes can be a quick and easy way to reach out to consumers from a different culture, but you will often end up losing customers as a result.

${ }^{35}$ Lipton, 18.

${ }^{36}$ Lipton, 17. 
Ineffective advertising is not always easy to spot for people who do not identify themselves as Latinos, especially for those who are not familiar with the culture. Hispanic Americans, however, can recognize subtle inaccuracies within advertisements. The key to successfully targeting the Hispanic audience is in the details - this is why research is so important. Many people can create ads that appear to reach the Hispanic consumer on the surface, but few take the time to actually understand the culture and all of the nuances that come together to create this unique demographic. Juan Tornoe, owner and senior consultant at Hispanic Trending comments: "When I moved to the U.S. ... it was immediately clear to me by my experience and by what I saw out there that people were not reaching out to Latinos at the customer-service level or at the marketing/advertising level as they should. Besides a culture shock, it was quite an impression...to say ‘Oh my gosh. People really have no clue."37 It is obvious to members of the Hispanic community when someone has taken the time to understand them and their background, and they will be more likely to buy products that accurately portray their culture and lifestyle.

After looking at both successful and unsuccessful designs concerning Hispanic Americans, it is easier to identify what makes for a "good" advertisement targeting Hispanics. The ads that appear to be successful incorporate some of the aspects of Hispanic culture discussed above in a subtle way, instead of in an overt and stereotypical manner. Knowledge of Hispanic culture should effect all decisions involved in creating designs. According to Lipton, you must "base your designs on insights into the audience. Then imbue these designs with subtle visual cultural cues." 38 Targeting this demographic

37 Latino Branding Power, "An Interview with Juan Tornoe."

38 Lipton, 9. 
requires a deeper understanding of the culture than fiestas and piñatas. It is necessary to understand their values and lifestyles in order to know what they will respond to. In addition, a more subtle approach to this demographic creates less of a barrier between Hispanic Americans and Americans from other backgrounds. Advertisements can reach out to a Hispanic audience while remaining relevant to all Americans.

This demographic responds to brands that attempt to connect with them and to build a relationship with them. Latinos are proud of their culture, and wish to support this pride in different ways, including buying brands that embrace their cultural background. According to Glenn Llopis, "Hispanics buy brands that empower their cultural relevancy...[they] represent a new type of consumer who is connected to their own cultural nuances that support the needs of their family, their heritage and customs." ${ }^{\prime 39}$ Many Hispanic Americans continue to identify with their Hispanic heritage, and look for products that indentify with the values that come along with this. According to Ronnie Lipton, "the most relevant designs are those that can capture what's unique about the consumer." 40 You need to identify what makes Hispanic Americans different from the rest of the country, what makes them special, and use this information in an educated and subtle manner in order to foster a connection with Hispanic consumers. Targeting the Hispanic consumer involves much more than translating advertisements and designs created for the majority into Spanish. Hispanic Americans are a part of a diverse and complex culture that provides them with a distinct and unique outlook on the world.

${ }^{39}$ Glenn Llopis, "Don't Sell to Me! Hispanics Buy Brands that Empower Their Cultural Relevancy," Forbes, May 14, 2012.

${ }^{40}$ Lipton, 11. 


\section{My Designs}

For the final component of this project, I created a series of ads that I believe effectively target the Hispanic audience, based on the insights mentioned above. I took all of my knowledge of Hispanic culture and design into consideration while working on my designs, and attempted to situate each decision I made within the context of the Hispanic market in the United States. These designs apply what I have learned from this project and provide a clearer picture of how to best target this demographic.

I first had to decide which product I was going to advertise. I chose Zevia soda, a soda sweetened with stevia that has zero calories and no artificial sweeteners. I decided to create ads for a soda brand because Latinos are expected to bring widespread growth to the beverage industry. According to Steve Mandala of Univision, “all of beverage marketers' growth will come from the Hispanic market." 41 This company could benefit greatly from reaching out to the Hispanic population in the United States, but they do not seem to have embraced this direction yet. This would be an especially effective brand for Spanishspeakers in United States, because 'Zevia' would not be difficult to pronounce in Spanish.

After choosing a product, I had to determine who my target audience was. Based on the strong influence of mothers in Hispanic households, mothers are most likely making the decision to buy the soda. Because of this, my target audience is Hispanic mothers, aged twenty-five through fifty. My strategic target, or a more focused view of the target audience, is young Hispanic mothers who are at least second generation Americans. My designs also target Mexican Americans specifically because the majority (65\%) of U.S.

41 Glenn Llopis, “5 Steps To Capturing The Hispanic Market - The Last True Growth Opportunity," Forbes, September 3, 2013. 
Latinos are of Mexican descent. ${ }^{42}$ Many of the designs and advertisements that I

encountered were aimed more towards Spanish-speaking consumers, so I decided to create ads in English in order to reach out more towards consumers that identify strongly with both Hispanic culture and the culture of the United States.

In order to develop a clearer idea of whom I was reaching out to with my designs, I created a consumer persona, or an example consumer from the target audience. I created the identity of Andrea Lopez, a thirty-five year old mother of three from Mercedes, Texas. Andrea is a stay-at-home mom whose main concern is her children's well-being and health. Her parents emigrated to the United States in the early 1970's from Mexico, and fostered an appreciation for Hispanic and Mexican culture in her that she desires to pass on to her children as well. She speaks Spanish, but is also fluent in English. This consumer persona creates a deeper and more personal view of the target audience, and prevents a shallow and detached understanding of the group.

After developing this persona, I found brands and ads that I believe Andrea would use or identify with. I included both designs that targeted Hispanics and those that did not, in order to provide a more complete view of her buying habits. This collection of images gave me a clearer idea of where Zevia needed to be situated among other brands that are popular among consumers within the target audience. I also examined the designs that I found to be successful in order to have a better understanding of how others are approaching similar issues. Many of these ads have won awards or come from agencies known for their work with Hispanics in the United States, and are a good source of

42 "Hispanic Americans By the Numbers." 
inspiration. All of these steps helped in understanding where Zevia should fit in among similar products.

Additionally, it was necessary to consider where the brand is now in order to determine what changes needed to be made. Figure 9 shows some examples of the company's current branding and advertisements. Many rely on a tagline of "Zero Calories. No Artificial Sweeteners," and they build heavily upon the concept of Zevia as a healthier alternative to regular sodas. Although some of their cans include bright colors, their branding has relatively mellow colors and a muted appearance. My goal was to transform Zevia into a more exciting brand that identified with Hispanic culture. Zevia's new approach is to appeal to Hispanic consumers without ostracizing consumers from other backgrounds.

First, I came up with a new tagline for the soda that more clearly highlighted the benefit for the consumer, instead of just the product attributes. Zevia's new tagline is "Happier and Healthier," which draws attention to the fact that Zevia is a healthier alternative to traditional soda brands such as Coca-Cola and Pepsi. Consumers do not have to feel as guilty about drinking Zevia as they would other sodas with high levels of sugar and calories. The attributes of zero calories and no artificial sweeteners are still implied, but they become secondary information that explains the emotional connection that the headline makes with the consumer.

Figures 10, 11, 12, and 13 show the designs that I developed for Zevia, which include a bus shelter sign, a billboard, a direct mail postcard, and a web banner. All of these mediums are capable of reaching a wide audience, and can be easily targeted towards specific groups. The billboard and bus shelter sign can be placed in an area with a high 
population of Latinos, the postcard can be mailed to residents in neighborhoods with large Hispanic populations, and the web banner can appear on websites frequented by Hispanic consumers. The ads target mothers, but in a playful way that reaches out to their children as well. They focus on the family by including the photo of the girl drinking the soda in many of the advertisements. They play on the value of family in Hispanic culture by appealing to a mother's desire to protect her children and keep them healthy.

Bright colors appear throughout the ads to create vibrant and attention-grabbing images. They include the blue background that was common in much of the previous marketing material, but I used a brighter blue in these new advertisements that is more appealing. The green bar that appears in every design connects with the green of Zevia's logo, and further emphasizes the healthier qualities associated with this beverage. The bright colors of the ads draw consumers' attention and are appealing to the Hispanic audience.

The leaf image taken from the logo also appears on every design to call to mind how this product is healthier than other alternatives. Leaves and other vegetation often connote health in designs, so I decided to play up this portion of the logo. The leaves also resemble the outlined forms found in many Hispanic designs. The circular bubbles appear throughout this system as well to help the consumer more clearly identify Zevia as a soda product. They establish a connection with the product design, because the bubbles also appear on Zevia cans.

These advertisements bring together many aspects of Hispanic culture and design in order to effectively target a Hispanic audience. They include subtle hints of Hispanic culture without deterring consumers of other cultural backgrounds. These designs show 
how to employ the values and characteristics of this demographic in an effective way in order to gain loyal Hispanic consumers.

As the Hispanic population in the United States grows larger every year, it is imperative that we continue to reach out to this demographic, and strive to improve the ways in which we do so. Latinos are becoming an extremely important and powerful sector of American culture and society, and targeting this market leads to many benefits for companies, as well as for the consumers involved. By gaining an understanding of this culture, you can determine how to target this demographic in a way that will leave the biggest impression and create a lasting relationship between the consumer and the brand. Although many companies are not taking advantage of this opportunity, more and more are beginning to understand the value of reaching out to this demographic. This project provides a broad overview of how to reach a Hispanic audience through design, but much more work can still be done in this area. We can always strive to develop a deeper understanding of this culture. Understanding another culture or demographic is difficult and it takes time, but the benefits that result from it are well worth the effort. 


\section{Appendix}

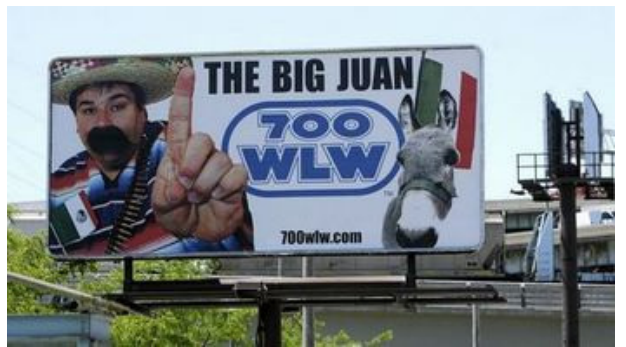

Figure 1. Billboard for Cincinnati radio station, n.d. Source: juantornoeblogs.com

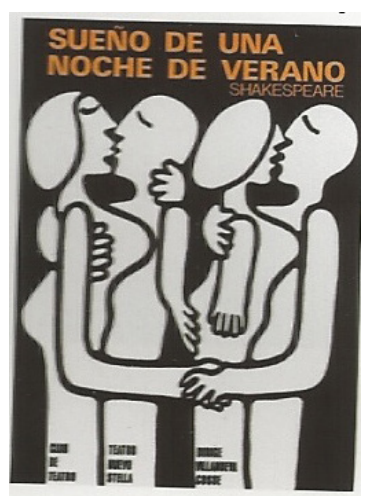

Figure 3. "Sueño de una noche de verano" poster, 1974, Club de Teatro de Montevideo, Carlos Palleiro, Uruguay.

Source: Latin American Graphic Design
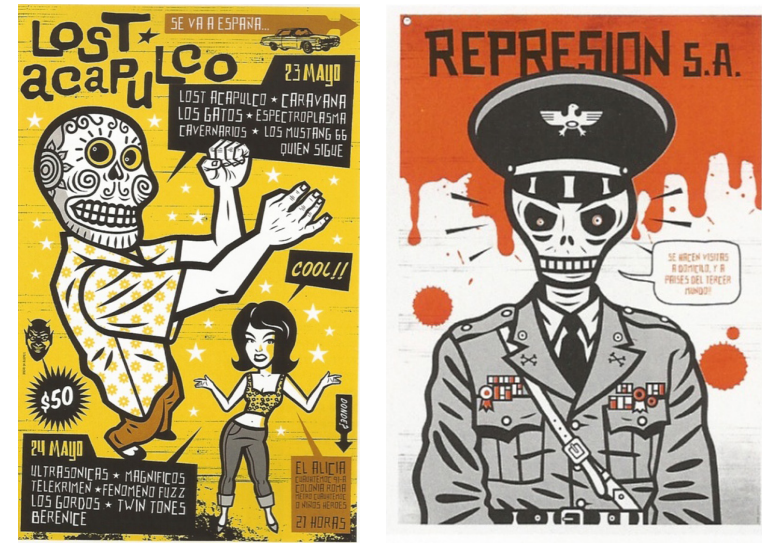

Figure 5. Left: "Day of Dead" Poster, 2003, Multiforo Cultural Alicia, Lost Acapulco.

Right: Represión S.A." poster, 2004, Hematoma Collective. Source: Latin American Graphic Design
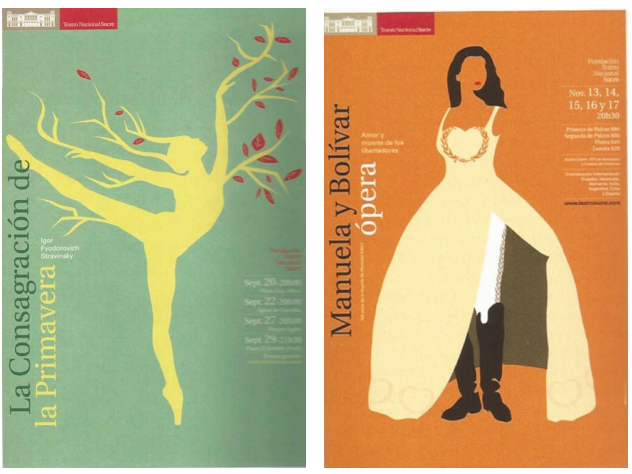

Figure 2. "Teatro Nacional Sucre" identity redesign and poster series, 2006, Fundación Teatro Nacional Sucre Source: Latin American Graphic Design

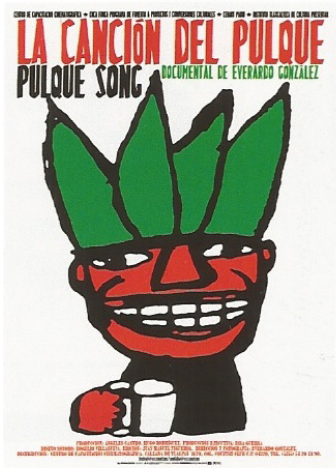

Figure 4. "La canción del pulque” film poster, 2003, Centro de Capacitación Cinematografía, Alejandro Magallanes, Mexico.

Source: Latin American Graphic Design

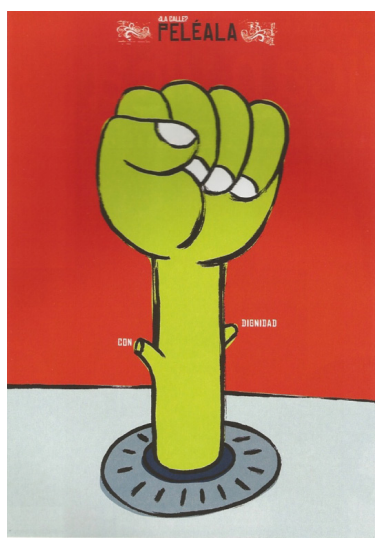

Figure 6. "La Calle, Peléala con dignidad" poster, 2005, Il Ibero-American Poster Biennial in Bolivia. Source: Latin American Graphic Design 


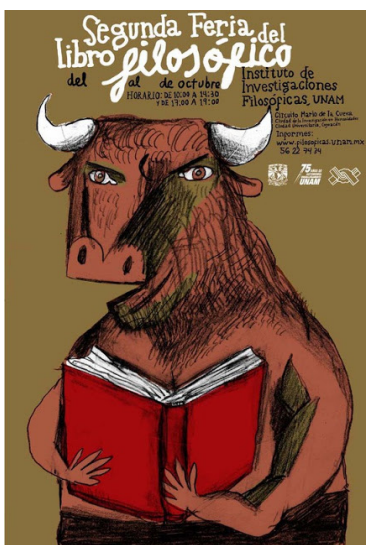

Figure 7. "Minotauro", Alejandro Magallanes Gonzalez, Poster for the Second philosophical Book Fair, organized by the UNAM Institute of Philosophical Research, n.d.

Source: guity-novin.blogspot.com

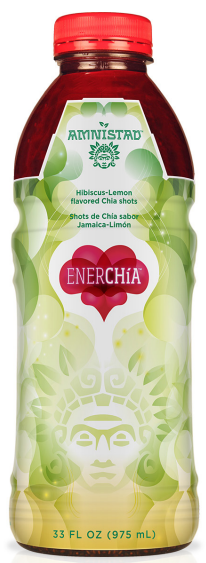

Figure 8. Amnistad, chia health drink packaging, Uno Branding, n.d.

Source: unobranding.com

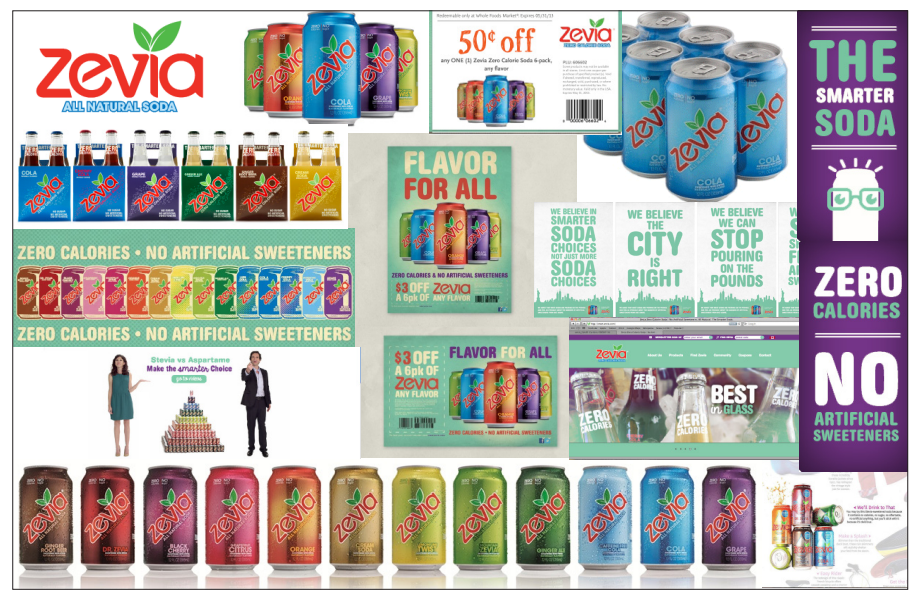

Figure 9. Zevia's existing brand. Source: zevia.com 


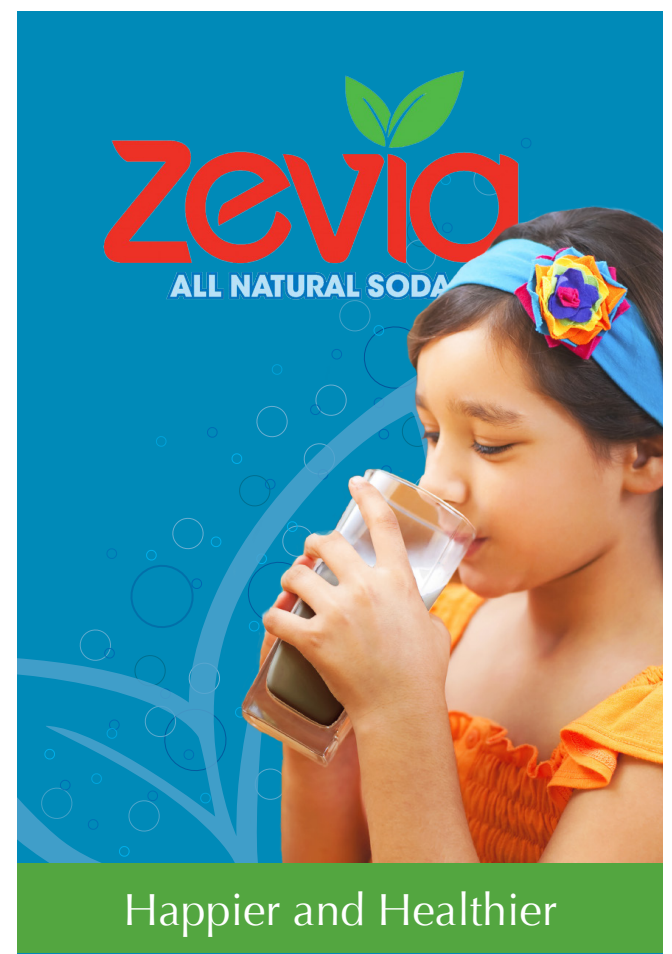

Figure 10. Bus Shelter Advertisement

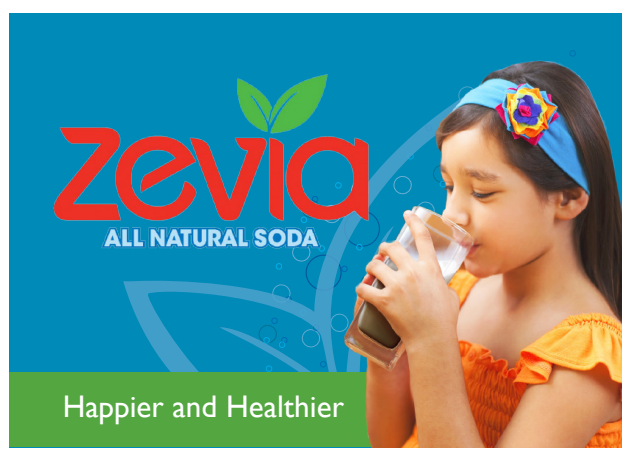

\section{zevia}

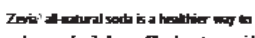

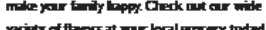

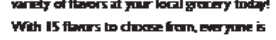

are to fird one the lonet

$\ulcorner------\overline{7}$
$\$ 3$ off a 6 pack of Zevía

Any Flavor

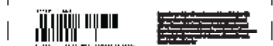

ᄂ $-----\ldots$

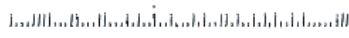

Figure 11. Direct Mail Postcard

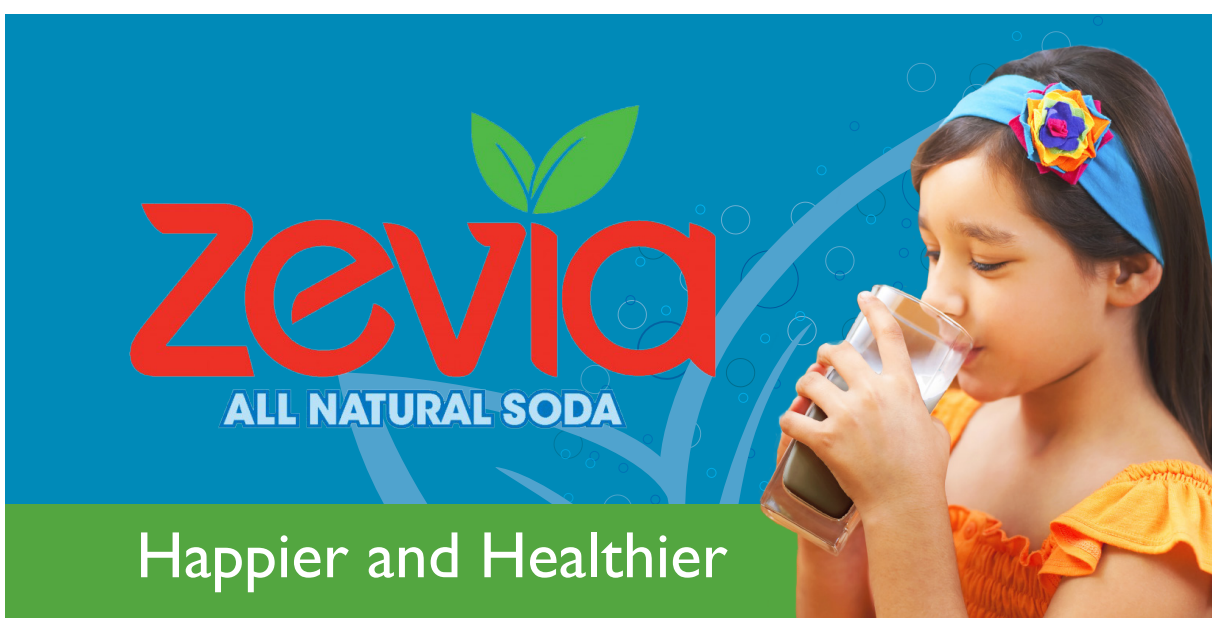

Figure 12. Billboard

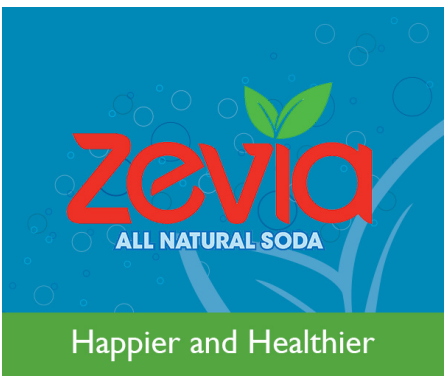

Figure 13. Web Banner 


\section{Bibliography}

"An Interview with Juan Tornoe." Latino Branding Power. March 28, 2011. Accessed February 21, 2013.

Cascón, Amparo L. "El Diseño Gráfico Latinoamericano." Cuadernos Hispanoamericanos 623 (2002): 85-94.

Delgado, Richard, and Jean Stefancic. The Latino/a Condition: A Critical Reader. New York: New York University Press, 1998.

Dias, Elizabeth. “Evangélicos.” Time Magazine, April 15, 2013. Accessed March 23, 2014. http://content.time.com/time/subscriber/article/0,33009,2140207-1,00.html.

"Educational Attainment in the United States: 2013." United States Census Bureau, last modified January 7, 2013. Accessed March 23, 2014. http://www.census.gov/hhes/socdemo/education/data/cps/2013/tables.html.

“Enerchia Health Drink.” Uno Branding. Last modified 2013. Accessed March 2, 2014. http://www.unobranding.com/uno/amnistad/.

Fox, Arturo A. Latinoamérica: Presente y Pasado. Upper Saddle River: Prentice Hall, 2011.

"Graphic design in Latin America, Part I; Colombia, Peru, Venezuela \& Mexico." A History of Graphic Design. Accessed March 3, 2014. http://guitynovin.blogspot.com/2011/12/graphic-design-in-latin-america-part-i.html.

Griffin, Charles C. Concerning Latin American Culture. New York, NY: Columbia University Press, 1940.

"Hispanic Americans by the Numbers." Infoplease. Last modified 2014. Accessed February 27, 2014. http://www.infoplease.com/spot/hhmcensus1.html.

"The Hispanic Population in the United States." United States Census Bureau, last modified November 6, 2012. Accessed September 7, 2013. http://www.census.gov/population/hispanic/data/2011.html.

Lipton, Ronnie. Designing Across Cultures. Cincinnati, OH: How Design, 2002.

Llopis, Glenn. "5 Steps To Capturing The Hispanic Market - The Last True Growth Opportunity.” Forbes. September 3, 2013. Accessed October 12, 2013

Llopis, Glenn. "Capturing the Hispanic Market will Require More Than a Total Market Strategy." Forbes. May 13, 2013. Accessed October 12, 2013 
Llopis, Glenn. "Don't Sell to Me! Hispanics Buy Brands that Empower Their Cultural Relevancy." Forbes. May 14, 2012. Accessed October 12, 2013

Lopez, Mark Hugo. "Hispanic or Latino? Many don't care, except in Texas." Pew Research Center, October 28, 2013. Accessed March 24, 2014. http://www.pewresearch.org/fact-tank/2013/10/28/in-texas-its-hispanic-porfavor.

Medina, Wanda. “Leading Role.” Latina, December 2013/ January 2014.

Noble, Judith, and Jaime Lacasa. The Hispanic way: aspects of behavior, attitudes, and customs in the Spanish-speaking world. Chicago, IL: Passport Books, 1991.

Olsen, Charlotte Shoup and Linda Skogrand. "Cultural Implications and Guidelines for Extension and Family Life Programming with Latino/Hispanic Audiences." The Forum for Family and Consumer Issues 14 (2009): 1. Accessed March 23, 2014. http://ncsu.edu/ffci/publications/2009/v14-n1-2009-spring/olsen-skogrand.php

Oxford Dictionaries. Accessed March 23, 2014. http://www.oxforddictionaries.com/us/definition/american english/stereotype.

PBS.“The Mexican American War.” Accessed March 23, 2014. http://www.pbs.org/wgbh/americanexperience/features/general-article/grantmexican-american-war.

Resano, Raquel Pelta. "El diseno en Espana - un siglo de diseno grafico en Espana." Cuadernos Hispanoamericanos 591 (1999): 23.

Rodriguez, Clara E. Latin looks: images of Latinas and Latinos in the U.S. media. Boulder, CO, 1997.

Stavans, Ilan. The Hispanic Condition: reflections on culture and identity in America. New York, NY: HarperCollinsPublishers, 1995.

Taborda, Felipe, and Julius Wiedemann. Latin American Graphic Design. Los Angeles, CA: Taschen, 2008.

Weyr, Thomas. Hispanic U.S.A.: Breaking the Melting Pot. New York, NY: Harper \& Row, 1988.

Zambrana, Ruth E. Latinos in American Society: Families and Communities in Transition. Ithaca, NY: Cornell University Press, 2011. 